\title{
4PL Suppliers Evaluating Indicator System Based on Grey Correlation Model
}

\author{
Yong $\mathrm{Ye}^{*}$ and Yuting Wu
}

Logistics Engineering, College of Computer and Information, Anhui Agriculture University, Anhui, Hefei, 230000, China

\begin{abstract}
The fourth party logistics which acts as a new role will increasingly play more and more important functions. In this paper, for a given deformation problems of 4PL providers' evaluation, We builds up a fourth party logistics evaluating indicator system based on four factors, which are quality, technical abilities, collaboration and price. Besides, we studies the analysis methods of grey correlation model and gives the definition of the correlation coefficient. Then we quantifies the index system and gives different weights to all evaluation indexes by calculating the grey relational grades. The studies show that different variable factors on the impact of choosing the fourth party logistics suppliers and it is more suitable in the practice than traditional methods.
\end{abstract}

Keywords: 4PL suppliers, correlation coefficient, grey correlation model, indicator system.

\section{INTRODUCTION}

The fourth party logistics (4PL) supplier is an integrator of supply chains, which integrates and manages different resources, abilities and technologies possessed by the company itself and complementary service suppliers, as well as provides a full set of solutions to supply chains [1]". Accenture consulting company proposed three possible applications or modes of 4PL: knowledge intensive, project-tailored and integration mode. Many companies are playing a crucial role by relying on 4PL suppliers, such as Manugistics Group Limited providing technologies to Amazon, i2 Technologies Inc. and JDA Software Group providing services to $3 \mathrm{M}$ Company, UCC.net Inc. and Vertical.net providing to WalMart. These technology suppliers are assumed to play a 4PL role, have extended the remit of 4PL to use it as a key element of their orientation and developmental targets.

In recent years, several factors have combined to create fertile ground for 4PL companies' growth, including: the growth discreteness and capability imbalance of 3PL suppliers; logistics management ability differentiation and the demand instability of industrial and commercial enterprises; a high deficiency of logistics professionals; an insufficient applicability of logistics information systems; and bottleneck problems in logistics infrastructure. In current practice, 3PL companies lack the strategic specialty of operating whole supply chains and related technology and, as such, actually integrating the supply chain process, while 4PL offers clients distinctive and extensive supply chains solutions by harnessing the best 3PL businesses, technology suppliers, management consultants and other value-added service suppliers, which is impossible for any single company to achieve.
Thus, methodically choosing 4PL suppliers in the process of establishing supply chains and evaluating their performance have become increasingly important aspects to consider.

To date, there have been few studies conducted on the evaluation system for 4PL suppliers' performance in China, mainly owing to the fact that $4 \mathrm{PL}$ has recently gained momentum there, with significant differences in the mode development. A significant proportion of 4PL suppliers working in the Chinese market have an IT background or have evolved from a 3PL businesses, while fewer 4PL businesses have the genuine capability of integrating all logistics resources. In addition, the logistics statistics system is very weak, making it difficult to generate a persuasive index evaluation system. In this paper, the author constructs evaluation principles and a theoretical model for 4PL suppliers, with reference to past study findings on performance evaluation of supplier subsystems, and further discusses the index weight's grey relationship methods. As for the question of whether or not choosing the 4PL, this is beyond the current discussions and potentially a subject for further research.

The earliest and most influential research on supplier selection is was carried out by Dickson (1996), who summarized 23 criteria for a supplier's performance evaluation by analyzing 170 questionnaires that were completed by purchasing agents and managers [2]. The findings revealed factors such as quality, delivery and previous performance to be very important. Following Dickson's study, Weber, Current and Benton conducted a literature review of 74 papers regarding the supplier selection process, and found that price was the most discussed element, followed by delivery, quality, production facility capacities, geographical location, technical competence, management and organization. By conducting surveys on 110 purchasing managers in the world's top 150 companies, Simpson (2002) analyzed the statistical data and pointed out that a continuously improving 
capacity, partnerships, customer relations, exchange factors, equipment and environment are also among the most significant indicators in evaluating a supplier's performance [3].

Based on those findings, we lists quality (focusing on service), technical competence, synergy and price as four crucial selection standards, and establishes a 4PL supplier's index evaluation system as follows:

(1) Quality: in contrast to the services provided by a third party, a 4PL supplier mainly offers comprehensive solutions and concentrates on intellectual resources support (including consulting, training, project management). In this context, clients' satisfaction level, management experience and credit rating are key indexes for reference.

(2) Technical competence: A 4PL supplier's capability in supply chains integration should be based on powerful information technology, while information systems compatibility (including abnormal situation treatment), advanced equipment and process design standardization are necessities for a professional consulting company.

(3) Synergy: a higher level of cooperation is needed if 4PL support is introduced, including clients' response rates, the coordination of business activities, and the controllability of supply chains.

(4) Price: it's necessary to consider costs when 4PL is introduced, up to and including considerations of the fourth party's financial and capital condition, in order to avoid certain risks.

In order to simplify the model and avoid relativity between the indexes, we use quality, technical competence, synergy and price as the common first-class indexes to examine one 4PL supplier's comprehensive competitiveness, and based on that set the first-class index variables. In practice, enterprises face the selection of several 4PL suppliers. For example, one enterprise may value such variable factors as research and development (R\&D) capability of the fourth party's technological indicators and information systems compatibility, while another may focus on advanced equipment and process design standardization for the same technological indicators. Hence, a subdivision of variable factors should be adjusted and set up in line with these varying corporate preferences. Furthermore, when companies investigate the influence of variable factors during certain time periods or compare the same first-class index among different 4PL suppliers, the following determination method for Grey Relationship Weight may be adopted.

\section{DETERMINATION METHOD FOR GREY RELA- TIONSHIP WEIGHT AND THE STEPS APPLIED}

A Grey Relationship refers to uncertain relationships between certain factors, such as, specifically, between systems factors and main behavior factors. The Grey Relationship analysis is a method for analyzing and determining the degree of influence between factors or factors' contribution in measuring the main behavior, based on a microcosmic or macroscopic approach of the behavioral factors sequence [4]. The method is mainly used in quantitative analysis of the dynamic development process of a whole system, as well as to determine index weights, which can be widely applied due to the unnecessary typical distribution rule resulting from incomplete sample information.

The traditional determination method for the grey relationship weight generally selects all indexes as a subsequence, and the indexes directly reflecting the evaluation purpose as a reference sequence; the method then builds in a grey relationship factors subset for the grey relationship space. Based on this, the grey relationship degree between each subsequence and reference sequence can be obtained, and each index weight may also be gained after sorting [5, 6]. The detailed steps are as follows:

(1) Set reference sequence or main sequence, expressed as $\chi_{0}=\left(x_{0}(1), x_{0}(2), \cdots, x_{0}(n)\right)$

(2) Set comparison sequence or subsequence, expressed as $\chi_{i}=\left(x_{i}(1), x_{i}(2), \cdots, x_{i}(n)\right), i=1,2, \cdots, m$.

(3) Calculate correlation coefficient by defining:

$\xi_{i}(k)=\frac{\min _{\mathrm{i}} \min _{\mathrm{k}}\left|\chi_{0}(\mathrm{k})-\chi_{\mathrm{i}}(\mathrm{k})\right|+\xi \max _{\mathrm{i}} \max _{\mathrm{k}}\left|\chi_{0}(\mathrm{k})-\chi_{\mathrm{i}}(\mathrm{k})\right|}{\left|\chi_{0}(\mathrm{k})-\chi_{\mathrm{i}}(\mathrm{k})\right|+\xi \max _{\mathrm{i}} \max _{\mathrm{k}}\left|\chi_{0}(\mathrm{k})-\chi_{\mathrm{i}}(\mathrm{k})\right|}$

As the correlation coefficient of $\chi_{i}$ with $\chi_{0}$ at time point $\mathrm{K}$, where $\xi$ is distinguishability, which is generally set as 0.5 .

(4) Calculate correlation degree by defining $\gamma_{\mathrm{i}}=\frac{1}{\mathrm{n}} \sum_{\mathrm{k}=1}^{\mathrm{n}} \xi_{\mathrm{i}}(\mathrm{k})$, as the correlation degree of $\chi_{i}$ with $\chi_{0}$.

Additionally, Bonian Li proposes a method to determine the index weight with vector cosine (hereafter referred to as the improved grey relationship method), which constructs optimal and pessimism sequences according to the index value of multiple index evaluation solutions. Li's method also calculates optimal and pessimism deviation rate matrixes and then, for each index, computes the cosine for the corresponding vectors of two matrices, and normalizes to obtain each index's weight [7]. Details of the improved grey relationship method are as follows:

(1) Generate the evaluation matrix. First, $m$ indexes are set for the index system with $n$ evaluation factors, so that an evaluation matrix is obtained as $A=\left(a_{i j}\right)_{m \times n}(i=1,2, \cdots, m ; j=1,2, \cdots, n)$, where $a_{i j}$ denotes an index value of the $\mathrm{j}$ evaluation factor for the $\mathrm{i}$ evaluation index, which is obtained after the initial data's dimensionless quantity treatment.

(2) Select reference sequences, including the optimal sequence $\vec{U}$ and pessimism sequence $\overrightarrow{\mathrm{L}}$, where $\overrightarrow{\mathrm{U}}=\left(u_{1}, u_{2}, \cdots u_{m}\right)^{T}$, and $\overrightarrow{\mathrm{L}}=\left(l_{1}, l_{2}, \cdots, l_{m}\right)^{T}$. When the index is benefit-oriented, the maximum optimal sequence $\vec{U}$ and the minimum pessimism sequence $\overrightarrow{\mathrm{L}}$ should be chosen. In contrast, if the index is cost-oriented, the minimum optimal sequence $\vec{U}$ and the maximum pessimism sequence $\vec{L}$ should be selected. 
(3) Determine the relative deviation matrix among $\vec{U}$ and $\overrightarrow{\mathrm{L}}$, including the optimal deviation matrix $R=\left(r_{i j}\right)_{m \times n}$ and pessimism deviation matrix $S=\left(s_{i j}\right)_{m \times n}$, where $r_{i j}=\frac{\mathrm{ua}_{\mathrm{ij}}}{\max _{\mathrm{j}}\left\{\mathrm{ua}_{\mathrm{ij}}\right\}-\min _{\mathrm{j}}\left\{\mathrm{ua}_{\mathrm{ij}}\right\}}$, $\left.s_{i j}=\frac{\mathrm{la}_{\mathrm{ij}}}{\max _{\mathrm{j}}\left\{\mathrm{la}_{\mathrm{ij}}\right\}-\min _{\mathrm{j}}\left\{\mathrm{la}_{\mathrm{ij}}\right\}}, i=1,2, \cdots, m ; j=1,2, \cdots, n\right)$, $u a_{i j}=\left|u_{i}-a_{i j}\right|, l a_{i j}=\left|l_{i}-a_{i j}\right|$.

(4) Set up each evaluation index's weight. First, calculate the cosine between row vector $r_{i}$ of $\mathrm{R}$ and the corresponding row vector $s_{i}$ of $\mathrm{S}$. That is $c_{i} \frac{\sum_{\mathrm{j}=1}^{\mathrm{n}} \mathrm{r}_{\mathrm{ij}} \cdot \mathrm{s}_{\mathrm{ij}}}{\sqrt{\sum_{\mathrm{j}=1}^{\mathrm{n}} \mathrm{r}_{\mathrm{ij}}{ }^{2}} \sqrt{\sum_{\mathrm{j}=1}^{\mathrm{n}} \mathrm{s}_{\mathrm{ij}}{ }^{2}}}$, and then normalize $c_{i}$ to obtain the indexes' weight vector $\varpi=\left(\omega_{1}, \omega_{2}, \cdots, \omega_{m}\right)$, where $\omega_{i}=\frac{\mathrm{c}_{\mathrm{i}}}{\sum_{\mathrm{i}=1}^{\mathrm{m}} \mathrm{c}_{\mathrm{i}}}$.

(5) Calculate the correlation coefficient matrix, including the optimal correlation coefficient matrix $\xi_{\mathrm{u}}=\left(\xi_{\mathrm{uj}}(i)\right)_{m \times n}$, and pessimum correlation coefficient matrix $\xi_{1}=\left(\xi_{\mathrm{lj}}(i)\right)_{m \times n}$. The calculation method is similar to Formula 1, where $\xi_{\mathrm{u}_{\mathrm{j}}}(i)$ and $\xi_{\mathrm{1}_{\mathrm{j}}}(i)$ represent the correlation coefficient between the $i$ index value in the $j$ solution vector $\overrightarrow{\mathrm{x}}_{\mathrm{j}}$ and the $\mathrm{i}$ index value $x_{i j}$ in the reference vector $\overrightarrow{\mathrm{U}}$, and the one between the $\mathrm{i}$ index value $u_{i}$ in the $\mathrm{j}$ solution vector and the $\mathrm{i}$ index value $l_{i}$ in the reference vector $\overrightarrow{\mathrm{L}}$, respectively.

(6) Calculate the correlation degree. The optimal correlation degree of solution $\mathrm{j}$ is $D(u, j)=\sum_{\mathrm{k}=1}^{\mathrm{n}} \xi_{\mathrm{u}_{\mathrm{j}}}(\mathrm{k}) \omega(\mathrm{k})$ or the pessimum correlation degree of solution $j$ is $D(l, j)=\sum_{\mathrm{k}=1}^{\mathrm{n}} \xi_{\mathrm{l}_{\mathrm{j}}}(\mathrm{k}) \omega(\mathrm{k})$ may be computed, and then the whole solution can be attained.

With respect to the specific evaluation models, we use the traditional grey relationship method to analyze the variation trend in the degree of correlation between variable factors at different time periods for a 4PL supplier's technology index, and the improved grey relationship method to evaluate the comprehensive indexes for several 4PL suppliers $[8,9,10]$. The following section provides the case numerical study.

\section{CASE NUMERICAL ANALYSIS}

1. Model 1: a certain 4PL supplier's technology index X (reference sequence) is mainly affected by R\&D ability, systematic equipment capacity and staff quality. Due to incomplete information, we first subdivide those three factors and then determine R\&D investment X (in RMB10,000), average staff years spent in education $\mathrm{X}$ (Year), information systems investment X (in RMB10,000), and achievements' marketization degree $\mathrm{X}$ as the comparative sequence's influence factors, to obtain the following numerical values shown in Table 1.

A dynamic matrix of the grey relationship can be obtained as follows with DSP, a software programme used in the Grey Relationship dynamic analysis:

$$
\left.\begin{array}{c}
\text { Time period } \\
2006-2014 \\
2006-2010 \\
2010-2014
\end{array} \quad \begin{array}{cccc}
\mathrm{X}_{1} & \mathrm{X}_{2} & \mathrm{X}_{3} & \mathrm{X}_{4} \\
0.82092 & 0.75555 & 0.86517 & 0.58921 \\
0.60320 & 0.59252 & 0.69111 & 0.49645 \\
0.63850 & 0.79502 & 0.64334 & 0.70269
\end{array}\right)
$$

The matrix indicates the influence of various variables on the technology index in the overall period and sub-period. During the overall period from 2006 to 2014, the impact on the technology indexes of the 4PL suppliers, from large to small, present as $X_{3}>X_{1}>X_{2}>X_{4}$, suggesting that the information systems investment has the largest effect, followed by R\&D investment and the staff's average number of years spent in education, while the achievements' marketization degree has the least influence. However, in the subperiod, that situation changes slightly, especially from 2010 to 2014, when the average number of years that staff spent in education rose to number one in terms of influence, followed by the achievements' marketization degree. This short is mainly owing to the fact that the earlier information systems investment requires workers with the corresponding technical competence, which then produces a more significant influence on the technology index with the recovery of the IT industry and the quality improvement of practitioners. From the initial data, we may see that with an improved staff educational level, the marketization degree of the suppliers' achievements also increases.

2. Model 2: Enterprises undertake a comprehensive evaluation based on the indexes of quality, technical competence, synergy and price for multiple 4PL suppliers. This evaluation matrix is shown in Table $\mathbf{2}$, where the rows represent the indexes and the columns represent the evaluation objects. For example, is expressed as the score of the $\mathrm{j}$ evaluation object with respect to the $\mathrm{i}$ index (the data are drawn from [7]).

(1) Determine the optimal and pessimism vectors with $\overrightarrow{\mathrm{U}}=(10.08,6.70,5.71,0.473)^{T}$, and $\overrightarrow{\mathrm{L}}=(5.2,3.75,3.30,1.599)^{T}$. It should be noted that quality, technology and synergy here are benefit-oriented indexes, while price is a cost-oriented one.

(2) Determine the relative deviation matrix among each solution $\overrightarrow{\mathrm{U}}$ and $\overrightarrow{\mathrm{L}}$ : 
Table 1. Technology index of 4PL supplier.

\begin{tabular}{|c|c|c|c|c|c|}
\hline Year & $X_{0}$ & $X_{1}$ & $X_{2}$ & $X_{3}$ & 8.12 \\
\hline \hline 2006 & 5.60 & 0.87 & 15.8 & 6.36 & 0.30 \\
\hline 2007 & 5.70 & 0.56 & 16.2 & 8.54 & 0.35 \\
\hline 2008 & 6.90 & 0.81 & 16.5 & 9.01 & 0.41 \\
\hline 2009 & 6.80 & 0.68 & 16.8 & 12.40 & 0.46 \\
\hline 2010 & 7.00 & 0.87 & 1.18 & 17.5 & 10.07 \\
\hline 2011 & 8.10 & 0.97 & 18.0 & 11.63 \\
\hline 2012 & 8.40 & 1.04 & 18.4 & 0.50 \\
\hline
\end{tabular}

Table 2. Comprehensive evaluation matrix for 4PL suppliers.

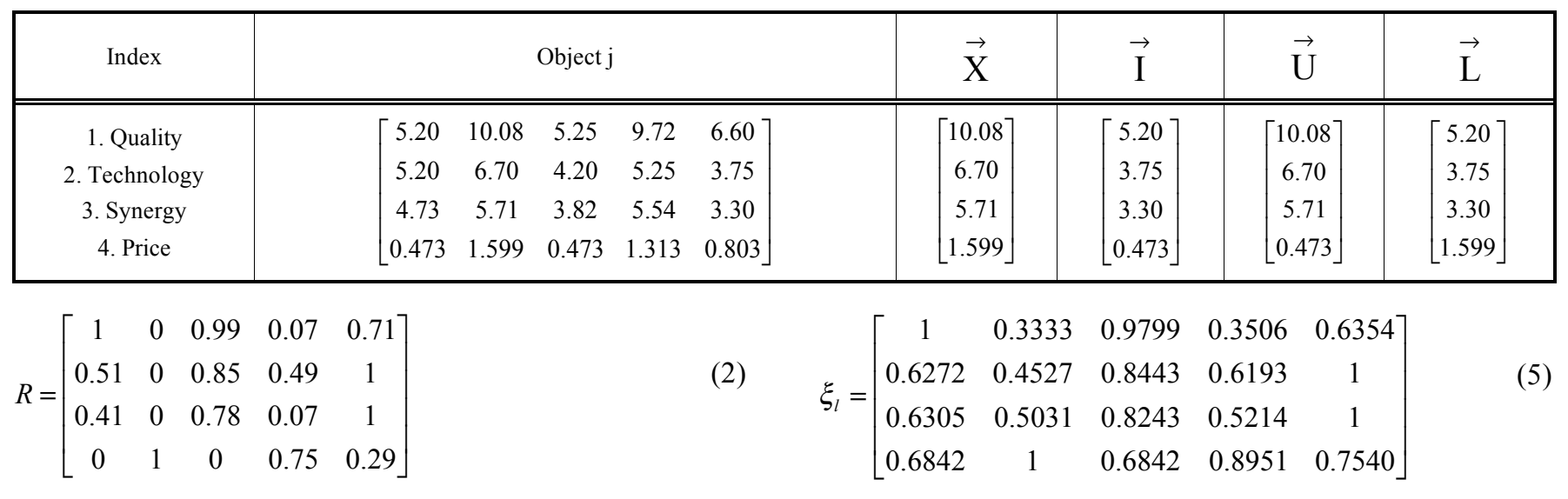

$S=\left[\begin{array}{ccccc}0 & 1 & 0.01 & 0.93 & 0.29 \\ 0.49 & 1 & 0.15 & 0.51 & 0 \\ 0.59 & 1 & 0.22 & 0.93 & 0 \\ 1 & 0 & 1 & 0.25 & 0.71\end{array}\right]$

(5) Calculate the correlation degree. The optimal correlation degrees of object $\mathrm{j}$ are $0.6848,0.9293,0.5982,0.7680$, and 0.5520 respectively, while its pessimism degrees are $0.6935,0.5663,0.8241,0.6080$, and 0.8952 respectively.

(6) Conclusions. The optimal correlation degree is orFor example: $r_{13}=\frac{|5.25-10.08|}{\Delta \max u-\Delta \min u=4.88}=0.99$.

(3) Calculate the weights, where:

$\overrightarrow{\mathrm{c}}=(0.1287,0.3422,0.2369,0.1933)$,

$\varpi=(0.1428,0.3798,0.2629,0.2145)$

(4) Calculate the correlation coefficient, where:

$\xi_{u}=\left[\begin{array}{ccccc}0.3333 & 1 & 0.3356 & 0.8714 & 0.4122 \\ 0.6193 & 1 & 0.4939 & 0.6272 & 0.4527 \\ 0.7135 & 1 & 0.5635 & 0.9349 & 0.5031 \\ 1 & 0.6842 & 1 & 0.7439 & 0.8809\end{array}\right]$ dered as $2>4>1>3>5$, while the pessimism correlation degree is ordered as $5>3>1>4>2$. Therefore, the enterprises may give priority to the second 4PL supplier.

According to model 1, enterprises may indirectly understand the influence of different variable factors on 4PL suppliers' technology index, which then provide evidence for management decisions. In addition, the enterprises may compare the variation trends in the variable factors when different 4PL suppliers have a similar technology index, in order to evaluate their advantages and weaknesses. However, according to model 2 , the enterprises not only obtained a single index's correlation degree of 4PL suppliers, but also the weight for each index, in order to finally achieve the trajectory of optimum to pessimism, displaying a wider applicable range compared with the traditional grey relationship method. 


\section{CONCLUSION}

(1) An objective weight determination process is needed when a 4PL's evaluation index system is constructed, and also in such a way that combines with an enterprise's practices when ready-made supply chain performance models such as SCOR and SCPR are used. The findings in this paper suggest, firstly, that the type of fourth party should firstly be determined (e.g. by importance, in which case it may be divided into preferred, important, commercial or partner; or by time span, such as short-term, long-term, permeationoriented, alliance-oriented or vertical integrated), according to the suppliers' relationship management rules. Secondly, the first-class index system should be decided with respect to different types of suppliers. Thirdly, variable factors should be selected based on the enterprises' preferences for building evaluation systems. As for whether or not the introduction of the 4PL and its evaluation should be conducted by the enterprise itself or outsourced to professional management consultants or financial consulting companies, the enterprises need to judge this on their own account [11].

(2) The enterprises should also pay attention to the shortterm and long-term behavior of the selected 4PL selected, and revise their evaluation system accordingly. As the fourth party has the ability to integrate management consultation and the 3PL suppliers' capabilities, serving as the only "connector" between clients and logistics information suppliers, they are arguably the leading logistics suppliers. In the short term, especially at the 3PL's initial or transitional stage, logistics business still plays a dominant role, resulting in the limited function of the fourth party in the sense that it will still take some time for the fourth party to progress from a main non-logistics business to the management epicenter throughout the supply chains. In the long run, due to larger demand elasticity for the fourth party, the enterprises' evaluation index preference will also change correspondingly, so the evaluation system needs to be revised in a timely manner.

(3) Ultimately, what the 4PL needs is simplicity and transparency, rather than just large size and comprehensiveness [12]. Although the benefits in adopting the solution provided by a single 4PL supplier lie in a unified systematic structure, relatively low support costs and average operating platform costs, there also exist certain risks in over-dependence on a single information system. More importantly, an unprecedented and unified technology solution to maximize clients' value requires a collaboration between consulting, technology and logistics companies to realize the full desired design, implementation and operation.

\section{CONFLICT OF INTEREST}

The authors confirm that this article content has no conflict of interest.

\section{ACKNOWLEDGEMENTS}

This work was financially supported by the Key Research Projects of Humanities and Social Science in the University of Anhui Province (SK2014A235) and the National Natural Science Foundation of China (No. 31371533).

\section{REFERENCES}

[1] S. K. Mukhopadhyay, and R. Setaputra, "The role of 4PL as the reverse logistics integrator: optimal pricing and return policies," International Journal of Physical Distribution \& Logistics Management,vol.36, no.9, pp.716-729, 2006.

[2] G. W. Dickson, "An analysis of vendor selection systems and decisions," Journal of purchasing, vol.2, no.1, pp. 5-17, 1966.

[3] P. M. Simpson, A. S. Judy, and C. W. Susan, "Measuring the performance of suppliers: an analysis of evaluation processes," Journal of Supply Chain Management,vol.38,no.4, pp.29-41, 2002.

[4] L. Shen, L. Olfata, K. Govindanb, R. Khodaverdi, and A. Diabat, "A fuzzy multi criteria approach for evaluating green supplier's performance in green supply chain with linguistic preferences," Resources, Conservation and Recycling,vol.74, pp.170-179, 2013

[5] N. K. Sahu, S. Datta, and S. S. Mahapatra, "Decision making for selecting 3PL service provider using three parameter interval grey numbers," International Journal of Logistics Systems and Management ,vol.14,no.3, pp.261-297, 2013.

[6] Ç. Erdal, H. Tozan, and O. Vayvay, "A method for selecting third party logistic service provider using fuzzy AHP," Journal of Naval Science and Engineering, vol.5,no.3, pp. 38-54, 2009.

[7] B. Li, "The Method of Determining the Objective Weight in MultPurpose Decision," Operations Research And Management Science,vol,11,no 5, pp.36-39, 2002.

[8] X. Zhang, J. Fang, and P. Liu, "A grey relational projection method for multi-attribute decision making based on intuitionistic trapezoidal fuzzy number," Applied Mathematical Modelling,vol.37,no.5, pp.3467-3477, 2013.

[9] A. Mohammad, D. Neagu, and I. C. Peter, "Fuzzy grey relational analysis for software effort estimation," Empirical Software Engineering,vol.15,no.1, pp.60-90, 2010.

[10] J. Hou, "Grey Relational Analysis Method for Multiple Attribute Decision Making in Intuitionistic Fuzzy Setting," Journal of Convergence Information Technology,vol.5,no.10, pp.194-199, 2010.

[11] S. H. Hashemi, A. Karimi, and M. Tavana, "An integrated green supplier selection approach with analytic network process and improved Grey relational analysis," International Journal of Production Economics, vol.159, pp.178-191, 2015.

[12] X. Zhang, J. Fang, and P. Liu, "A grey relational projection method for multi-attribute decision making based on intuitionistic trapezoidal fuzzy number," Applied Mathematical Modelling, vol. 37,no. 5, pp. $3467-3477,2013$. 